\title{
Implementasi Kebijakan Publik Dalam Pembangunan Ruang Publik Pantai Losari Makassar
}

\author{
Ondang Surjana \\ Pasca Sarjana, Universitas Swadaya Gunung Jati, Cirebon \\ Email: ondangsur@gmail.com
}

\begin{abstract}
ABSTRAK
Kebijakan publik serta implementasinya merupakan sebuah program yang komplek karena perlu melibatkan seluruh stakeholder, yaitu pihak pemerintah, publik dan swasta. Kebijakan publik terdiri dari banyak aktor dengan berbagai kepentingannya tetapi publik sebagai target sasaran sehingga menjadi aspek yang paling penting.

Ruang publik merupakan salah satu sarana fisik yang dalam pembangunannya memerlukan sebuah kebijakan publik. Ruang publik adalah sebuah barang publik yang dibangun oleh pemerintah bagi kepentingan publik. Ruang publik dapat diakses bebas dan digunakan oleh seluruh warga kota dan fungsi utamanya sebagai tempat interaksi sosial. Keberadaan ruang publik sangat penting bagi warga kota dan merupakan salah satu elemen kota. Ironisnya, jumlah ruang publik di kota kota besar menurun.

Pantai Losari, Makassar, adalah salah satu ruang publik yang paling populer dan paling banyak dikunjungi masyarakat setempat maupun dari daerah lain. Ruang publik tersebut merupakan ruang publik utama di Kota Makassar serta sebagai landmark kota.

Daya tarik utamanya adalah lokasinya yang strategis berada di pinggir pantai. Ruang publik pantai Losari dibangun dengan menggunakan gaya arsitektur modern dipadukan dengan elemen elemen estetis tradisional. Tujuannya agar dapat mengakomodir beragam etnis di kota tersebut. Pada dasarnya pantai Losari adalah hasil implementasi kebijakan publik.

Kata kunci: kebijakan publik, implementasi, ruang publik, arsitektur modern.
\end{abstract}

\begin{abstract}
Public policy and its implementation is a complex program because of the need to involve all stakeholders, namely the government, public and private. It consists of many actors with different interests but the public as a target to become the most important aspect. Public space is one of the physical facilities in a city which its development requires a public policy. Public space is a public goods built by the government for public purposes. It can be free accessed and used by citizens and its primary function as a place of social interaction. The existence of public space is very important for the citizens of the city and is one important elements of the city. Ironically, the amount of public space in big cities declined.

Pantai Losari, Makassar, is one of the most popular public space and most visited by local communities and other areas. This is a major public space in Makassar city as well as a city landmark. Its main attraction is its strategic location at the seaside. Pantai Losari built using modern architectural style combined with traditional aesthetic elements. The goal is to be able to accommodate diverse ethnicities in the Makassar. Basically, Pantai Losari is the result of the implementation of public policy.
\end{abstract}

Keywords: public policy, implementation, public space, modern archtecture. 


\section{PENDAHULUAN}

Kebijakan publik serta implementasinya merupakan sebuah program yang komplek karena perlu melibatkan seluruh stakeholder, yaitu pihak pemerintah, publik dan swasta. Tujuannya agar sebuah program publik dapat memenuhi kepentingan semuanya, seperti dinyatakan berikut ini"Kajian mengenai sektor publik membutuhkan metode yang lebih lengkap dengan alasan bahwa sektor publik terdiri dari banyak aktor dan kepentingan yang beragam“ [1]. Hal ini disebabkan persoalan publik yang bersifat bermacam-macam, kompleks, multi perspektif dan sebagainya. Kompleksitas masalahnya tersebut telah mendorong penerapan kebijakan publik yang tepat sasaran, menggunakan pendekatan holistik agar mampu mengakomodir kepentingan seluruh stakeholder.

Ruang publik (public space) merupakan salah satu sarana fisik yang dalam pembangunannya memerlukan sebuah kebijakan publik. Ruang publik termasuk salah satu barang publik (public goods) yang dibangun oleh pemerintah bagi kepentingan publik. Pengertian barang publik adalah"Pure public goods have two defining features. One is 'non-rivalry', meaning that one person's enjoyment of good does not diminish the ability of other people to enjoy the same good. The other is 'non-excludability', meaning that people cannot be prevented from enjoying the good" [2]; Pendapat lainnya mengenai barang-barang publik adalah "Public goods are those for which consumption by one individual dose not reduce availability to others. Within typical urban economy, there is a whole range of goods that contain elements of 'publicness' in that their production, while not necessarily benefiting everyone equally, does allow consumers other than those willing and able to pay to gain considerable benefit from their use"[3]. Dalam kaitannya dengan penyediaan ruang publik, pihak pemerintah idealnya mampu mengakomodir seluruh kebutuhan warganya yang memiliki status sosial yang berbeda, terutama kalangan masyarakat kelas menengah ke bawah. Pada dasarnya keberadaan ruang-ruang publik tersebut sangat dibutuhkan oleh warga kota. Bahkan menjadi salah satu komponen kota yang tidak dapat dipisahkan.

Kota Makassar adalah Ibu Kota Provinsi Sulawesi Selatan dan termasuk salah satu kota besar di Wilayah Timur Indonesia. Jumlah penduduknya sekitar 1,6 juta jiwa dengan luas wilayah 199,26 km2. Penduduknya berasal dari berbagai latar belakang etnis, budaya, sosial, pendidikan, ekonomi dan lain-lain. Pantai Losari adalah ruang publik utama di Makassar yang memiliki lokasi sangat strategis berada di pinggir pantai [12].

\section{TINJAUAN PUSTAKA}

\subsection{Kebijakan Publik}

Terdapat banyak pengertian atau definisi mengenai kebijakan publik. Salah satu pengertian kebijakan publik adalah berkaitan dengan tindakan pemerintah, yaitu "The term public policy always refers to the actions of government and the intentions that determine those actions. Making policy requires choosing among goals and alternatives, and choice always involves intention" [3]; Menurut Dye kebijakan publik adalah "Whatever governments choose to do or not to do". Sedangkan James E. Anderson mendefinisikan kebijakan sebagai perilaku dari sejumlah aktor (pejabat, kelompok, instansi pemerintah) atau serangkaian aktor dalam dalam suatu bidang kegiatan tertentu. Pembicaran tentang kebijakan tidak terlepas dari kaitan kepentingan nilai kelompok, baik di tingkat pemerintahan maupun masyarakat secara umum"[1]; "Kebijakan publik bervariasi menurut wilayah yang diintervensi, tujuan yang ingin dicapai, kelompok sasaran yang dituju, dan substansi perubahan yang diharapkan. Berbagai variasi tersebut menyebabkan jenis kebijakan yang lebih mudah diimplementasikan dibanding dengan kebijakan yang lain"[4]; Pengertian lainnya adalah "..., maka yang ditekankan disini adalah masalah, kebutuhan dan aspirasi dari masyarakat yang seharusnya dilayani. Isu penting yang sering munucl adalah sudahkah kebijakan public merespons secara baik aspirasi, kebutuhan dan 
masalah yang dihadapi masyarakat?" [5]; Laswell memperkenalkan sebuah model proses kebijakan yang terdiri dari tujuh tingkatan, yaitu 1) intelligence, 2) promotion, 3) prescription, 4) innovation, 5) application, 6) termination, dan 7) appraisal. The model itself has been highly successful as a basic framework for the field of policy studies and become starting point of a variety of typologies of the policy process" $[6]$.

Pengertian aktor atau stakeholder adalah orang-orang yang akan terpengaruh, mungkin mempengaruhi, mereka yang tertarik dengan sebuah kebijakan, ataupun orang yang mempunyai kemampuan untuk mempengaruhi proses kebijakan. Barangkali mereka adalah perseorangan, kelompok, pemerintah, departemen pemerintah, asosiasi, perusahaan, komunitas dan sebagainya. Pernyataaan di atas menunjukkan bahwa pengertian stakeholder sangat beragam.

\subsection{Analisis Kebijakan Publik}

Analisis kebijakan publik adalah "Policy analysis is principally concerned with describing and investigating how and why particular policies are proposed, adopted, and implemented. A policy option mist be evaluated in the light of what policy analysis reveals about its chances of being adopted, the probable effectiveness of the option, and the difficulties of implementation"[3]. Dunn mendefinisikan analis kebijakan sebagai "An applied social source discipline which uses multiple methods of inquiry and arguments to produce and transform policy-relevant information that may be utilized in political setting to resolve policy problems"; Menurut Lowi dan Ginsburg analisis kebijakan adalah "An officially expressed intention backed by a sanction, which can be reward or punishment". As a course of action (or inaction), a public policy can take the form of a law, a rule, a statute, an edict, a regulation or an order" [7]; Saat ini terdapat kecenderungan analisis kebijakan baru yang menekankan pada aspek manajerial, yaitu "Policy analysis, as it known today, has taken an empirical orientation geared more to managerial practices than to facilitation of demographic government per $s e$ "[7]; Menurut Purwanto bahwa analisis kebijakan ditinjau dari sudut fungsinya, yaitu " Pertama, sektor publik secara nyata memiliki tingkat kompleksitas yang lebih dari pada sektor privat. Artinya sektor publik yang terdiri dari banyak aktor dan kepentingan membutuhkan metode yang lebih lengkap untuk menyelesaikan masalah yang dihadapinya. Kedua, sektor publik memiliki resiko lebih tinggi untuk menghadapi masalah-masalah yang tidak dapat diprediksi. Artinya sektor publik lebih memiliki peluang untuk mendapatkan masalah-masalah baru dari kondisi yang tidak dapat diprediksi sebelumnya. Ketiga, sektor publik memiliki ruang lingkup masalah yang lebih luas dari pada sektor privat. Artinya, pemerintah membutuhkan pertimbangan-pertimbangan yang lebih memiliki cakupan luas, dan pertimbangan-pertimbangan yang lebih kompleks dari pada analisis kebijakan yang dimiliki oleh sektor privat" [4].

\subsection{Implementasi Kebijakan Publik}

Menurut Püzl bahwa implementasi adalah "Implementation studies are to be found at the intersection of public administration, organizational theory, public management research, and political science studies. In broadest sense, they can be characterized as studies on policy change"[8]; Menurut Santosa bahwa "Implementasi kebijakan adalah aktivitas-aktivitas yang dilakukan untuk melaksanakan suatu kebijakan secara efektif. Implementasi ini merupakan pelaksanaan aneka ragam program yang dimaksudkan dalam suatu kebijakan"[9]; Menurut King dan Stivers (1998) bahwa implementasi mendesak agar para administrator melibatkan warga masyarakat. Mereka harus melihat rakyat sebagai warga masyarakat (bukan sebagai pelanggan) sehingga dapat saling membagi otoritas dan melonggarkan kendali, serta percaya terhadap keefektifan kolaborasi. Keterlibatan masyarakat harus dilihat sebagai "investasi" yang signifikan [5]; Menurut Warwick implementasi adalah "Implementations means transaction. To carry out a program, implementers must continually deal with tasks, environments, clients, and each other. The formalities of organizations and the mechanics of administration are important as background, but the key to success is continual coping with context, personalities, alliances, and events. And crucial to such adaptation is willingness to 
acknowledge and correct mistakes, to shift directions, and to learn from doing. Nothing is more vital to implementation than self correction; nothing more lethal than blind preservation" [4]; Menurut Sabatier dan Mazmanian terdapat faktor-faktor berdampak pada proses implementasi, yaitu 1) factor affecting the tractability of the problem, 2) non statutory variable affecting implementation, and 3) the ability of the statute to structure implementation "[9]; Sedangkan Christopher Hood menawarkan konsep perfect implementation, yaitu: "One way of analyzing implementation problems is to begin by thinking about what perfect administration would be like, comparable to the way in which economist employ the model of perfect competition. Perfect administration could be defined as a condition in which external elements of resource availability and political acceptability combine with administration, to produce perfect policy implementation "[10] ; Definisi implementasi kebijakan yang lebih luas adalah: "What happens between the establishment of an apparent intention on the part of the government to do something, or to stop doing something, and the ultimate impact in the world action" [6]; Sebuah proses implementasi kebijakan yang ideal mencakup elemen-elemen utama berikut: 1) Specification of program details (i.e., how and by which agencies/organization should the program be executed? How should the law/ program be interpreted?);2) Allocation of resources (i.e., how are budgets distributed? Which personal will execute the program? Which units of an organization will be in charge for the execution?); 3) Decisions (i.e., how will decisions of single cases be carried?)"[6].

Dalam implementasinya sebuah kebijakan publik harus sinergis, terdapat kesesuaian antara masyarakat sebagai target sasaran dengan pihak birokrat sebagai implementor program. Mengenai adanya kegagalan pemanfaatan yang optimal sebuah ruang publik dapat disebabkan oleh berbagai faktor, antara lain rendahnya sosialisasi program tersebut. Sehingga publik tidak memahami tujuan atau fungsi ruang publik tersebut secara tepat. Selain itu adalah lemahnya pengawasan termasuk pemeliharaan oleh pihak pemerintah sebagai implementor program. Pada umumnya faktor pemeliharaan, misalnya di dalam menjaga kebersihan, melakukan pemungutan sampah dan melakukan perbaikan kerusakan fisik sangat minim dilakukan oleh kalangan aparat pemerintah. Sebagai tambahan, lemahnya mekanisme pengawasan terhadap gangguan, tindakan vandalisme terhadap ruang publik. Demikian pula, lemahnya pengawasan dalam proses pembangunannya dapat menyebabkan hasilnya tidak optimal, pemakaian bahan yang tidak sesuai spesifikasi dan sebagainya.

Sebenarnya dalam program implementasi kebijakan publik peranan masyarakat sangat terbuka. Kesempatan ini didorong oleh kemunculan era demokrasi dan konsep governance yang memberikan ruang partisipasi masyarakat. Sebagai sebuah konsep governance dirancang dengan pemikiran pokok, perlunya mengakhiri dominasi negara dalam pembuatan kebijakan dan eksekusinya [4]. Konsep di atas telah membuka ruang dan peran stakeholder lainnya, yaitu sektor swasta dan masyarakat sipil dalam kewenangan ekonomi, politik dan administrasi. Kecenderungan sekarang ini adalah model implementasi multiple agencies yang melibatkan banyak aktor dan lembaga. Pendekatan ini disebabkan oleh kompleksitas persoalan publik yang menuntut keterlibatan banyak pihak. Namun terdapat gejala bahwa dalam implementasi sebuah kebijakan publik setiap aktor memiliki kepentingan sendiri yang dapat berbenturan kepentingan satu sama lainnya. Hal ini yang menyebabkan implementasi sebuah kebijakan publik tidak mudah.

Selanjutnya studi implementasi mengalami perkembangan cukup pesat, terutama di dalam rangka merespon perkembangan dinamika jaman dan masyarakat. Perkembangan yang terakhir mengenai studi implementasi telah diarahkan atau didorong menjadi lebih scientific dan mengikuti perubahan mengenai publicness. Paradigma baru tersebut dengan menggunakan istilah Denhardt dan Denhardt adalah dari paradigma old public administration menuju new public management dan selanjutnya new public service.

\subsection{Ruang Publik}

Pengertian sebuah ruang publik (public space) sangat beragam dan luas. Oleh karena itu, pemahaman tentang ruang publik dan fungsinya belum sepenuhnya dipahami oleh masyarakat maupun pemerintah sebagai penyedia dan pengelolanya. Ruang publik adalah sebuah tempat bagi publik atau warga kota 
dalam melakukan aktivitas dan interaksi sosial. Salah satu definisi ruang publik adalah " The modern city and its expansion, associated with the problems of special segregation, social polarization and privatization of space...The uses of public space in social cohesion and reintegration, as well as in economic regeneration of cities are examined to find out about the contested social, economic and political role of the public realm in the contemporary city"[10]; Beberapa kriteria sebuah ruang publik, yaitu "In each instance the term 'public space' is used to designate a location which is (i) designed, however minimally, such that (ii) everyone has the rights of access, (iii) encounter in it between individual users are unplanned and unexceptional, and (iv) their behavior towards each other is subjected to rules no one other than those of common norms of social civility"[11]; Menurut Stephen Carr bahwa ruang terbuka publik merupakan ruang wadah aktivitas sosial yang melayani dan juga mempengaruhi kehidupan masyarakat kota. Ruang terbuka juga merupakan wadah dari kegiatan fungsional maupun aktivitas ritual yang mempertemukan sekelompok masyarakat dalam rutinitas normal kehidupan sehari-hari maupun dalam kegiatan periodik. Ia pun menjelaskan terdapat macammacam tipologi ruang terbuka publik, yaitu taman-taman publik (public parks), lapangan dan plaza (square and plaza), taman peringatan (memorial parks) pasar (markets), jalan (streets), lapangan bermain (playground), ruang terbuka untuk masyarakat (community open spaces), jalan hijau dan jalan taman (green ways and park ways), atrium/pasar tertutup (atrium /indoor markets place), pasar / pusat perbelanjaan pusat kota (market place / down town shopping center), tepi laut (water fronts) "[11]; Sedangkan jenis-jenisnya antara lain "Public spaces (including high streets, street markets, shopping precincts, community centers, parks, play grounds and neighborhood space in residential areas) play a vital role in the social life of communities. They act as self organizing public service, a shared resource in which experiences values are created" [9].

\subsection{Fungsi dan Peranan Ruang Publik}

Ruang publik memiliki fungsi utama, yaitu memberikan akses bebas bagi siapa pun yang memasuki dan menggunakannya. Hal ini pula yang membedakannya dengan ruang-ruang privat atau ruang berbayar. Disamping itu, menurut Siahaan[13] bahwa ruang publik ditandai oleh tiga hal, yaitu 1) responsif, 2) demokratis, dan 3) bermakna. Responsif dalam arti bahwa ruang publik adalah ruang yang dapat digunakan untuk berbagai kegiatan dan kepentingan luas, demokratis artinya ruang publik dapat digunakan oleh masyarakat umum dari berbagai latar belakang sosial, ekonomi dan budaya serta aksesibel bagi berbagai kondisi fisik manusia. Bermakna memiliki arti kalau ruang publik harus memiliki tautan antara manusia, ruang dan dunia luas dengan konteks social [13]. Ia pun menambahkan bahwa disamping ruang publik yang khusus dibangun atau diperuntukkan aktivitas publik, terdapat pula tempat-tempat yang dapat berfungsi sebagai ruang publik, yaitu “....bahwa ruang terbuka hijau (open space) publik seperti jalan dan taman serta ruang terbuka non-hijau publik seperti tanah perkerasan (plaza) dan public squares dapat difungsikan sebagai ruang publik. Sedangkan fungsi atau keuntungan dari sebuah ruang publik adalah "Public spaces offer many benefits : the "'feel-good" buzz from being part of a busy street scene; the therapeutic benefits of quiet time spent on a park bench; places where people can display their culture and identities and learn awareness of diversity and difference; opportunities for children and young people to meet; play or simply 'hangout' all have important benefits and help to create local attachments, which are at the heart of a source of community" [12].

\section{METODOLOGI}

Metode penelitian yang digunakan adalah deskriptif, yaitu "Descriptive research attempts to describe systematically a situation, problem, phenomenon, service or program, or provides information about, say, living condition of community, or describes attitudes towards an issue" [14]. Dalam penelitian deskriptif hanya menjelaskan fenomena yang terjadi saat ini tanpa meneliti latar belakang terjadinya gejala-gejala tersebut. 
Jenis penelitiannya studi kasus "Case studies, on the other hand, are often seen as prime examples of qualitative research - which adopts an interpretative approach to data, studies 'things' within their context and considers the subjective meanings that people bring to their situation" [15].

\section{HASIL DAN PEMBAHASAN}

Perkembangan kota-kota besar di Indonesia menunjukan gejala dinamis mengikuti perkembangan jaman, teknologi dan masyarakatnya. Disamping itu, banyak kota kondisinya semakin kompleks menghadapi berbagai permasalahan, terutama mengenai pertumbuhan penduduk dan keterbatasan lahan. Hal ini menyebabkan semakin padatnya kota-kota besar terutama di pusat kota dan pusat bisnis. Faktor penyebab lainnya adalah urbanisasi, kegiatan bisnis, aktivitas sosial, aktivitas keagamaan dan sebagainya. Hampir seluruh aktivitas di atas memerlukan lahan yang diperuntukan membangun sarana-sarana bagi kegiatan-kegiatan di atas. Contohnya pembangunan gedung perkantoran, pusat perdagangan, fasilitas transportasi, sarana pendidikan, sarana olah raga, komplek perumahan dan sebagainya.

Pada hakekatnya manusia sebagai makhluk sosial yang memerlukan medium atau ruang untuk melakukan interaksi sosial dengan yang lain. Salah satunya melalui fasilitas ruang -ruang publik. Kebutuhan ini terutama bagi kalangan masyarakat menengah ke bawah karena mereka memiliki keterbatasan biaya di dalam mengakses atau menggunakan ruang-ruang privat atau semi privat. Ruang publik seperti Alun-alun, taman kota, plaza, lapangan olah raga, RTH, tempat rekreasi merupakan sebuah alternatif di dalam mengimbangi kesibukan dan kepenatan di kalangan penduduk kota besar. Ironisnya, prosentase jumlah dan luas ruang publik di berbagai kota besar menunjukkan penurunan, tidak seimbang dengan kebutuhan minimal.

Selama ini pengertian sebuah ruang publik berbeda-beda di kalangan masyarakat, antara lain ada yang beranggapan bahwa ruang publik dapat digunakan untuk semua aktivitas, baik rekreasi maupun ekonomi seperti berjualan atau berdagang. Sebenarnya ruang publik utamanya diperuntukan untuk kegiatan sosial, seperti berinteraksi dengan cara mengobrol, bercanda, olah raga dan sebagainya. Namun fenomena yang umum terjadi di sebagian besar ruang-ruang publik di Indonesia adalah pemanfaatan untuk berjualan atau berdagang. Kegiatan usaha ini banyak dilakukan oleh pedagang kaki lima atau pedagang asongan. Sehingga luas sebuah ruang publik menjadi menyempit, kecil atau bahkan terserobot. Selain menyebabkan kuantitasnya berkurang juga kualitasnya menurun karena suasananya menjadi kurang nyaman, kurang tenang ataupun kotor akibat sampah.

Pantai Losari yang terletak di sebelah Barat Kota Makassar adalah salah satu ruang publik yang paling populer dan paling banyak dikunjungi masyarakat setempat maupun dari daerah lain. Ruang publik tersebut merupakan ruang publik utama di Kota Makassar serta berperan sebagai landmark kota. Daya tarik utamanya adalah lokasinya yang strategis berada di pinggir pantai. Ruang publik Pantai Losari dibangun dengan menggunakan gaya arsitektur modern sehingga tidak berbeda kondisi dan tampilannya dengan ruang publik di kota besar lain. Pembangunan proyek tersebut dimulai sejak tahun 2006 dan diselesaikan selama 8 tahun. Luas areanya 11 hektar dengan total anggaran Rp.39,75 miliar. 


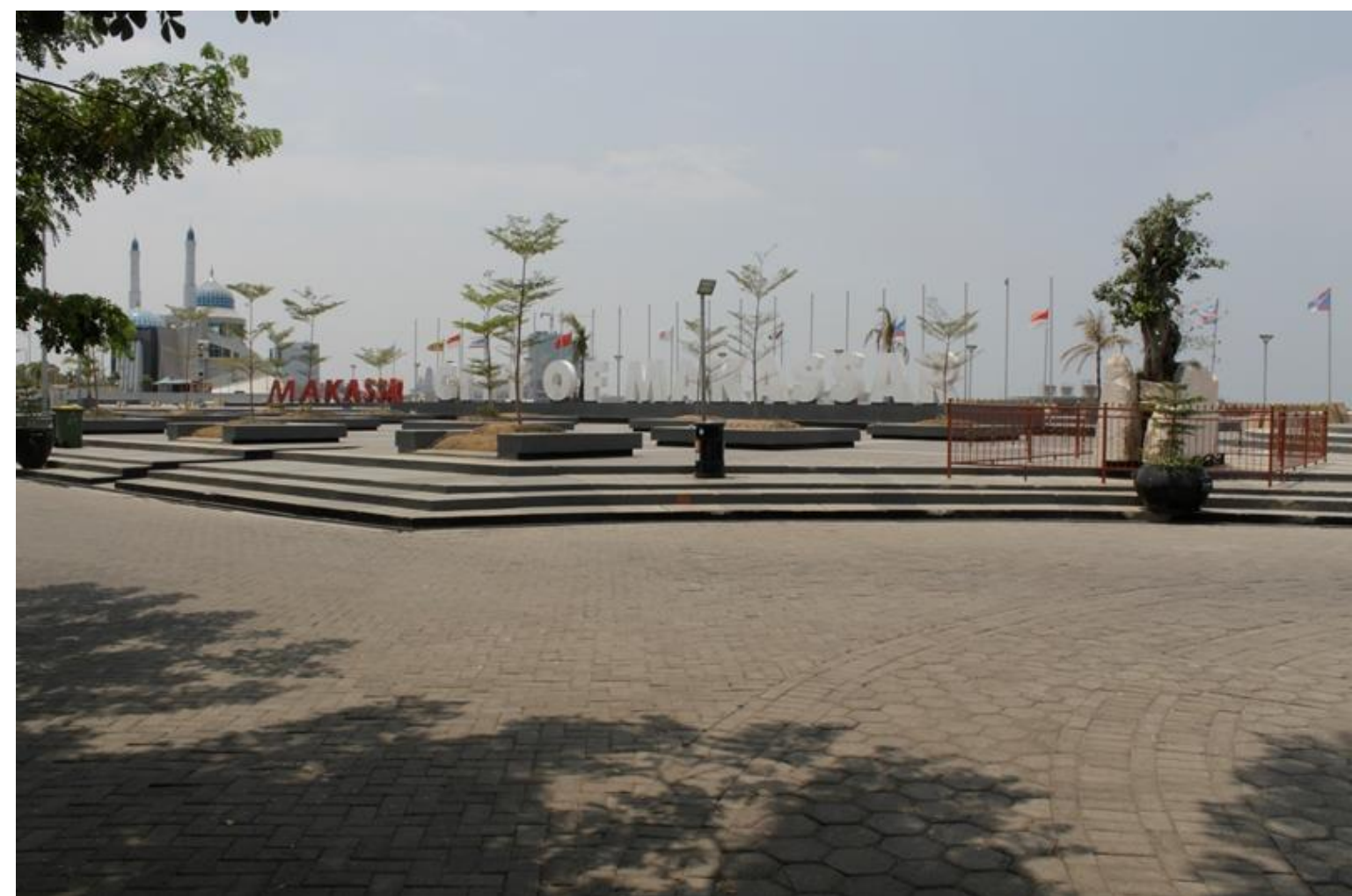

Gambar 1 Pantai Losari, Makassar, merupakan ruang publik utama sebagai fasilitas sosial publik dirancang dengan gaya arsitektur modern.

Selama ini pantai Losari berfungsi sebagai ruang publik yang diperuntukkan untuk berbagai kegiatan atau interaksi sosial warga kota Makassar. Ruang publik di atas terdiri dari 4 anjungan, yaitu 1) anjungan Metro yang berbentuk segitiga, 2) anjungan Pantai Losari, 3) anjungan Toraja-Mandar, dan 4) anjungan Bugis-Makassar. Ruang publik ini seluruhnya bergaya arsitektur modern dengan menggunakan elemen-elemen estetik tradisional. Konsepnya adalah untuk mengakomodir budaya dan tradisi etnis-etnis yang terdapat di Makassar. Namun secara keseluruhan menampilkan gaya arsitektur modern.
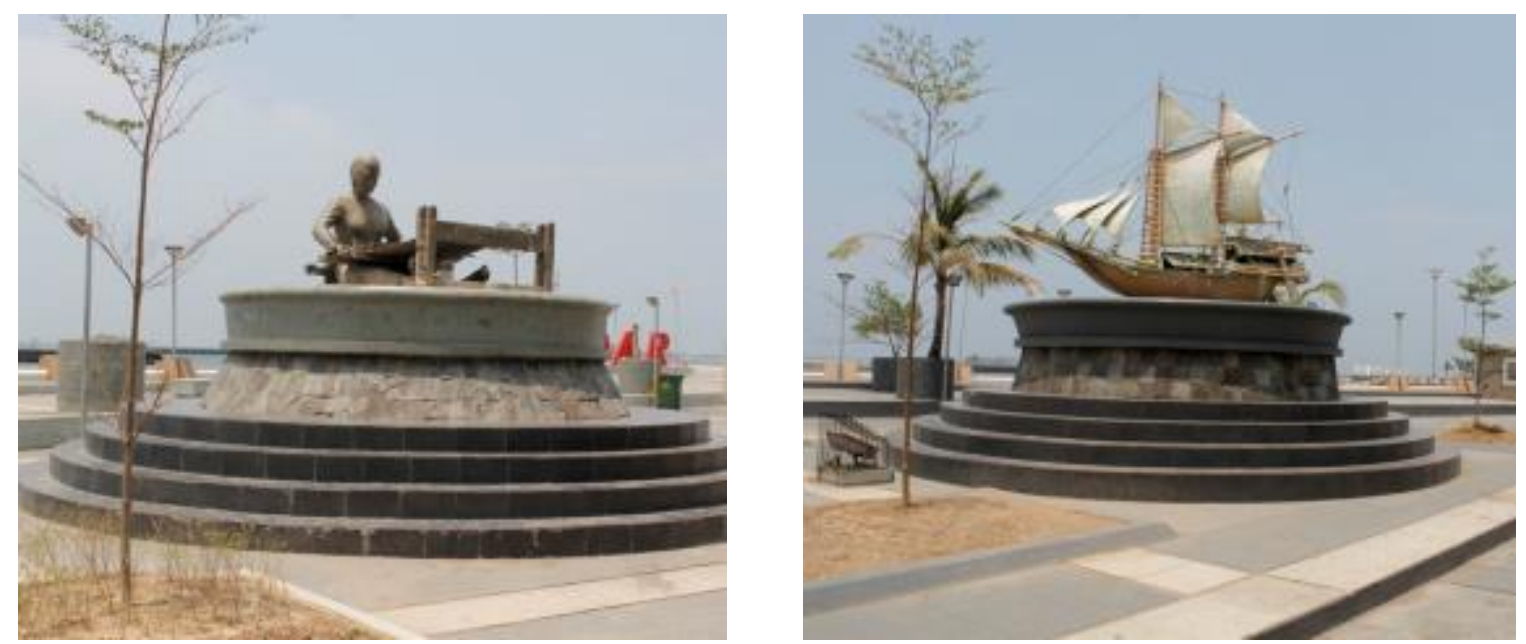

Gambar 2 Setiap anjungan dibedakan dengan menempatkan ciri khas atau identitas daerahnya. Sebuah cara untuk mengakomodir publik yang beragam dalam sebuah ruang publik.

Mengenai peraturan ruang terbuka hijau di Kota Makassar adalah sebagai berikut "Berdasarkan Peraturan Daerah (Perda) Makassar No. 6/2006 tentang Rencana Tata Ruang Wilayah Kota Makassar 
Tahun 2005-2015 prosentase luas ruang terbuka hijau pada kawasan pusat kota ditargetkan sebesar 5\% dari luas kawasan pusat kota dengan arah pengembangannya, antara lain mengembangkan jalur hijau berbunga sepanjang koridor jalan dan hijau produktif di pekarangan rumah, mempertahankan lahan pemakaman dan lapangan olah raga yang ada, serta melestarikan taman lingkungan di area pemukiman" [12]. Secara umum keberadaan ruang-ruang publik maupun RTH semakin minim "Saat ini keberadaan ruang publik maupun Ruang Terbuka Hijau (RTH) di kota-kota besar di Indonesia, seperti di Jakarta, Surabaya, Medan dan Bandung, luasan RTH telah berkurang dari 35\% pada awal tahun 1970-an menjadi kurang dari 10\% pada saat ini“ (Siahaan:4). Namun menurut pendapat Siahaan bahwa contoh pengembangan ruang publik yang berhasil adalah ruang publik di Pantai Losari, Makassar. Selain lokasinya yang strategis juga memiliki sejarah yang panjang mengenai pantai tersebut. Oleh karena itu, pembangunan ruang publik Pantai Losari oleh pemerintah kota Makassar merupakan program kebijakan publik yang tepat.

\section{SIMPULAN}

Permasalahan kebijakan publik maupun implementasinya di lapangan bersifat dinamis dan komplek. Implementasinya memerlukan pendekatan holistic yang mencakup seluruh aspek, termasuk mengakomodir kepentingan seluruh stakeholdernya, yaitu pemerintah, masyarakat dan swasta. Peranan publik dalam sebuah kebijakan sangat penting karena sebagai target sasaran sebuah program.

Ruang publik adalah ruang interaksi sosial masyarakat. Peranan ruang publik, misalnya taman kota, sangat dibutuhkan oleh masyarakat terutama bagi kalangan menengah ke bawah. Jumlah dan luas ruang-ruang publik di kota-kota besar menunjukan penurunan. Sementara penduduk kota terus meningkat terus, termasuk akibat urbanisasi dan penggunaan untuk kepentingan bukan sosial.

Pantai Losari, Makassar, adalah salah satu ruang publik terbaik di Indonesia. Ruang publik tersebut berusaha mengakomodir seluruh etnis dan tradisi masyarakat setempat melalui penempatan elemenelemen estetik. Namun secara keseluruhan ruang publik tersebut dirancang dengan gaya arsitektur modern.

\section{DAFTAR PUSTAKA}

[1] Indiahono. (2009). Kebijakan Publik Berbasis Dynamic Policy Analysis. Yogyakarta: Gava Media.pp.1,17.

[2] Kotchen. (2012). Public Goods. Yale University.pp. 2

[3] Cochran, Clark., E, Meyer, Lawrence., C, Carr, T., Cayer, Joseph., N. (2009). American Public Policy. An Introduction. Ninth Ed. Canada: Wadsworth, Cengage Learning. pp.104, 7.

[4] Purwanto, Erwan, Agus., Sulistyastuti, Ratih., Dyah. (2012). Implementasi Kebijakan Publik. Konsep dan Aplikasinya di Indonesia. Yogyakarta: Gava Media.pp. 24-25, 1-3, 21,15.

[5] Keban, Jeremias., T. (2008). Enam Dimensi Strategis Administrasi Publik. Konsep, Teori dan Isu. Edisi ke-2. Yogyakarta: Penerbit Gava Media.pp. 7, 247.

[6] Fischer, Frank., Miller, Gerald, J., Sidney, Mara, S.eds. (2007). Handbook of Public Policy Analysis. Theory, Politics, and Methods. Boca Raton, FL: CRC Press. pp. xix.

[7] Püzl, Helga., Treib, Oliver. (2007).Implementing Public Policy.In Handbook of Public Policy Analysis. Theory, Politics, and Methods.Fisher, Frank et al. Eds. Boca Raton, FL: CRC Press.pp.89.

[8] Santosa, Pandji. (2012). Administrasi Publik. Teori dan Aplikasi Good Governance. Bandung: Refika Aditama. Pp.43.

[9] Hill, Michael., \& Hupe, Peter. (2002). Implementing Public Policy: Governance in Theory and in Practice, London: SAGE Publications. pp.49,51. 
[10] Madanipour, Ali. (2003). Public and Private Spaces of the City. London and New York: Routledge.pp.193.

[11] Huat, Beng, Chua., Edwards, Norman. (1992). Public Space: Design, Use and Management. Singapore: Singapore University Press.pp. 2.

[12] Asmaulany, A.: (2014). Identifikasi Tingkat Penggunaan Ruang Terbuka Publik di Kota Makassar, Dilihat Dari Aspek Aktivitas, Fasilitas dan Kriteria Perancangan. Jurnal Teknosains : Vol. 8, No. 1. Pp. 2,3-4.

[13] Siahaan, James. (2008). Ruang Publik : Antara Harapan dan Kenyataan. 2

[14] Research Methodology.tanpa tahun.www.explorable.com/research.pp.4

[15] Kendal, Simon.(2015). How to Write a Research Paper. $1^{\text {th }}$ Ed. Bookboon.com. 